\title{
The Eye of the Farmer and Detection of Animals in Need of Anthelmintic Treatment in Organic Meat Sheep Flocks
}

\author{
M. Bouilhol ${ }^{1}$, M. Foessel $^{1}$ and J. Cabaret ${ }^{*}, 2$ \\ ${ }^{I}$ Département Agricultures et Espaces, VétAgro Sup, BP 35, 63370 Lempdes, France \\ ${ }^{2}$ INRA, UR 1282, IASP 213, 37380 Nouzilly, France
}

\begin{abstract}
Organic meat sheep producers are limited by their access to and permitted use of synthetic drugs to effectively control internal parasites, and they are limited further still, by the narrow array of efficient alternative drugs available to them. The use of targeted selective treatments, for the control of parasites, e.g. treating only the lambs that cannot cope with infection, would be of interest. The difficulty is in identifying those specific lambs in need of treatment. FAMACHA ( ) (an anaemia indicator) has been used with success in tropical areas where the blood sucking worm Haemonchus contortus is the main gastrointestinal nematode. From their own experience, farmers may also be able to detect lambs in poor, average or good condition, possibly relative to parasite infection burden, a method referred to as farmers' eye score. Using the farmers'eye score to judge lambs in need of treatment was not found to be fully efficient. It was however, significantly related to the presence of Moniezia eggs and to the number of Trichuris and possibly Nematodirus eggs in faeces but remained unrelated to the excretion of other gastrointestinal nematode eggs. The farmers'eye score was in agreement with the average faecal egg counts but the accuracy of individual detection of lambs in need of treatment, remained low (49\% correctly classified). The FAMACHA ${ }^{\circ}$ had an even lower efficiency to detect lambs requiring treatment. The farmers'eye score when correcting for farm variability was improved and highly correlated to the infection with Nematodirus. The farmers'eye score should be improved using pathophysiological indicators (diarrhoea score, weight gains..) or/and by harmonisation among farmers, if it is to be relied upon to detect animals in need of anthelmintic treatment in the future.
\end{abstract}

Keywords: Parasitism, Meat sheep, FAMACHA ${ }^{\circledR}$, Organic, Farmers'eye.

\section{INTRODUCTION}

Gastrointestinal parasites of meat sheep represent a major pathological and production problem for grazing lambs. They present an even greater challenge to organic meat sheep [1] since the principle of organic farming is to limit the use of synthetic anthelmintics. Although the European regulations permitted the use of anthelmintics without limitation in 2010, organic farmers still aim for a reduction in their use. They cannot fully rely upon alternative treatments or the management of pastures as a control method [2] and instead still depend on synthetic anthelmintics for the control of gastrointestinal parasites. Ideally, their use of anthelmintics would be kept to a minimum. Two possible options are offered: Targeted Treatment (TT); using the anthelmintic for the whole flock at the optimum moment to interrupt parasite transmission or Targeted Selective Treatment (TST); treating only those sheep in need of treatment. Both strategies have their merits [3] and TST further requires the correct identification of sheep in need of treatment. Among the identification methods in detecting sheep in need of treatment, the most widely used has been the anaemia indicator FAMACHA ${ }^{\odot}$ [4], particularly in tropical areas where the blood sucking

*Address correspondence to this author at the INRA, UR 1282, IASP 213, 37380 Nouzilly, France; Tel: +33 2 47427768; Fax: +33 2 47427774;

E-mail: jcabaret@tours.inra.fr nematode Haemonchus contortus is highly prevalent. Organic farmers are more inclined to incorporate TST strategies than conventional farmers [5], and the study will therefore focus on sheep from organic farms only. Although farmers agree with selective treatment strategies, they can be reluctant to use the pathophysiological indicators proposed by scientists. Instead, they prefer to rely on their own abilities to detect the animals in need of treatment [6], a method that will be referred to as the farmers'eye score. A preliminary investigation was conducted into two organic farms, in which the evaluation was performed by both the farm shepherd and by an outside shepherd. The agreement between the two shepherds regarding sheep condition was low (50\%) (Nicourt, personal communication, 2009). This indicates that an evaluation of the farmers' ability and consistency in detecting target treatment animals is required, and thus forming the basis of this study [7]. In the present experiment, 18 organic meat sheep farmers were asked to classify their grazing lambs into three categories, good, average and poor as based on their own criteria (e.g. general aspect of the lamb, social and feed behaviour, quality of the wool, vigour, strength etc.), the idea being that the lambs in the poor category would be those with heavier parasite burdens and those which should therefore be selected for treatment with anthelmintics [8]. The aim of the research was to compare the farmers'eye score with the actual infection indicator (faecal egg counts) and anaemia indicator $\left(\right.$ FAMACHA $^{\circledR}$ ). 


\section{MATERIALS AND METHODS}

\section{Farms and Sampling}

The 18 organic meat sheep farms were located within three departments from the Centre of France (Haute-Vienne, Allier, Puy de Dome). The maximum distance between farms was $150 \mathrm{~km}$. The altitude of each department was 200, 200-350 and 800-1000 m, respectively. The mean yearly temperatures of each department were 11-12, 12-13 and 10$11{ }^{\circ} \mathrm{C}$, respectively. The farms were chosen on their willingness to participate in the study and on the basis that organic breeding practices had been in place for more than 5 years. The majority of farms did not introduce new sheep from other sites and their internal parasitism could be considered to be related only to their own practices. The helminth fauna observed in sheep from the area at the beginning of summer constituted principally of gastrointestinal nematodes (Teladorsagia, Trichostrongylus and Haemonchus representing $10-15 \%$ of the gastrointestinal community), Nematodirus, and the cestode Moniezia [8]. Flock size ranged from 250 to 580 ewes. Breeds of sheep included: Ile de France, Limousine, Hampshire, Suffolk, Clun Forest, Bizet, and crossbreds. Most of the lambings took place between February and April. Following lambing, ewes were fed on permanent pasture or meadows, on regrowth of silage in June and on regrowth of hay in July. After weaning, lambs were grazed on pasture and their diet supplemented with cereals and dehydrated alfalfa (a total of 20 to $30 \mathrm{~kg}$ was supplied up to the age of 4 to 6 months). No anthelmintic treatments were used on any lamb before the two evaluation visits in June and July. On each visit, the farmers'eye score (from 1-good to 3-poor), FAMACHA ${ }^{\circ}$ score (from 1- excellent to 5- animal is in great danger) were established. Faecal samples were randomly collected in each farm from approximately 10 lambs in June and July and. 11 to $24 \mathrm{EPG} / \mathrm{OPG}$ were available per farm.

\section{Faecal Egg Counts}

A derived McMaster floatation method [9] was used to determine eggs per gram of faeces (EPG) or coccidian oocysts per gram of faeces (OPG). The floatation liquid was magnesium sulphate. The method was sensitive to 50 eggs of helminths or 100 coccidian oocysts per gramme of faeces; anything less than $50 \mathrm{EPG} / 100 \mathrm{OPG}$ went undetected. The eggs were classified in the following categories: gastrointestinal nematodes (GIN), Nematodirus (NEM), Trichuris (TRIC) and Strongyloides (SGD). The oocysts of coccidia (COC) were also counted. The Moniezia (MON) eggs were not counted and only their prevalence was recorded.

\section{Statistical Analyses}

General linear model on log transformed data was used to detect the putative importance of sampling month and farm on the EPG and OPG [10]. The parasitic characterization of the farms was further achieved using principal component analysis [11]. The nonparametric correlation of Spearman $\left(r_{s}\right)$ and Kruskall and Wallis test were used to investigate the relationship of farmer's eye score and intestinal helminth/coccidian EPG or OPG [10]. The classification value of the farmers'eye score in relation with internal parasites EPG or OPG was tested with a linear discriminant analysis or a multinomial regression [10].

\section{RESULTS}

\section{Intestinal Parasitism in Farms}

Collectively for all farms, the average EPG of gastrointestinal nematodes was 1103, Nematodirus 116, Trichuris 67 and Strongyloides 400. The coccidian oocysts averaged to 18158 OPG. Moniezia was observed in $27 \%$ of the lambs. A GLM was undertaken on the individual transformed EPG values to estimate the relative importance of farm factor (e.g. the general management of animals, the breed, type of pasture etc.) and month of sampling (June and July). Farm was a significant factor for all parasites ( $\mathrm{p}$ from 0.00 to 0.02). Conversely sampling month had some importance on NEM only. The two sampling months were then regrouped and related to the farmers'eye score. The infection intensity (EPG and OPG) and parasites genera varied from one farm to another (see Table 1). A principal component analysis was carried out on standardized EPG (Fig. 1). The first axis and the second axis represented 41 and $24 \%$ of variance, respectively. The main variables acting on axis 1 (PCA variable loading) were GIN, NEM and TRIC (positively) and Coc (negatively). The main variables of axis 2 constituted MON (positively) and TRIC (negatively). Two groups of farms were distinguished according to the dominant parasites; the first dominated largely by $\mathrm{COC}$ and the second by helminths.

\section{Farmers'Eye Score in Relation to Parasite EPG/OPG and FAMACHA ${ }^{\circledR}$}

Famacha $^{(}$was not correlated positively and significantly to a higher GIN or any other intestinal parasite, on an individual lamb basis. The farmers' eye score was only significantly and positively related to $\operatorname{SGD}\left(\mathrm{r}_{\mathrm{s}}=0.17 ; \mathrm{p}=0.02\right)$. The average values of parasites EPG and FAMACHA ${ }^{\circledR}$ are presented in Table 2. The classification by farmers' eye score and FAMACHA $^{\circ}$ were contradictory. The most severe anaemia score was found among the lams judged by farmers to be in good condition.. Moniezia was more prevalent and TRIC EPG higher in farmer's eye score up two and three. Discriminant analysis showed the farmers' eye score classified $49 \%$ lambs in need of treatment adequately. FAMACHA $^{\odot}$ was less efficient with $39 \%$ correctly classified. A multinomial regression of farmers' eye score on EPG of helminth and OPG of coccidia $(\mathrm{p}=0.13)$ provided a pseudo R square of Cox and Snell of 0.03 for 387 lamb samples. Since farmers'eye score may be different from one farm to another $\mathrm{d}$ /or may depend on the level of infection, multinomial regressions including the farm factor were implemented for GIN over 200 to over 1500 (Table 3). The regressions were all significant and NEM and Farm were always the significant variables.

\section{DISCUSSION}

The higher faecal egg counts on certain farms compared to others within the area [5], may indicate poor general management of the farms [2]. The FAMACHA ${ }^{\odot}$ produced poor scores as a pathophysiological indicator. FAMACHA ${ }^{\odot}$ has previously been demonstrated to be particularly efficient 
Table 1. Parasitic Description of the Farms Based on Faecal Samples in June and July (Average and Standard-Deviation for GIN, NEM, TRIC, SGD-EPG, COC-OPG; Prevalence for MON)

\begin{tabular}{|c|c|c|c|c|c|c|}
\hline Farm Number (No. of Samples) & GIN & NEM & TRICc & SGD & MON & $\mathrm{COC}$ \\
\hline $1(15)$ & $2837(1808)$ & $277(496)$ & $451(529)$ & $169(175)$ & 20 & $7538(6704)$ \\
\hline $2(19)$ & $103(132)$ & 0 & $70(165)$ & $24(27)$ & 21 & $7870(12183)$ \\
\hline $3(22)$ & $1417(1745)$ & $77(92)$ & $23(46)$ & $148(198)$ & 0 & 39395 (55187) \\
\hline $4(19)$ & $1120(972)$ & $201(255)$ & $4(14)$ & $125(168)$ & 63 & $26288(57183)$ \\
\hline $5(13)$ & $1756(1691)$ & $251(243)$ & $46(95)$ & $12(34)$ & 38 & $14658(17008)$ \\
\hline $6(22)$ & $100(123)$ & $44(83)$ & $12(28)$ & $18(64)$ & 9 & $31416(81071)$ \\
\hline $7(20)$ & $1312(1939)$ & $30(55)$ & $196(423)$ & $83(141)$ & 5 & $490(967)$ \\
\hline $8(20)$ & $405(634)$ & $137(266)$ & $16(44)$ & $104(193)$ & 35 & $21005(30861)$ \\
\hline $9(11)$ & $71(108)$ & 0 & 0 & 0 & 0 & $27202(63246)$ \\
\hline $10(18)$ & $258(386)$ & $43(60)$ & $35(50)$ & $205(425)$ & 22 & $10352(10675)$ \\
\hline $11(21)$ & $1397(2765)$ & $22(39)$ & $69(91)$ & $213(914)$ & 0 & $11290(15155)$ \\
\hline 12 19) & $1864(1745)$ & $11(32)$ & $96(102)$ & $13(25)$ & 47 & $4746(4331)$ \\
\hline $13(20)$ & 3099 (4094) & $197(825)$ & $126(123)$ & $1036(1289)$ & 45 & 8198 (6573) \\
\hline $14(24)$ & $425(501)$ & $248(242)$ & $15(37)$ & $14(24)$ & 63 & $13950(12558)$ \\
\hline $15(17)$ & $631(760)$ & 0 & $1(5)$ & $1331(2684)$ & 18 & $16312(36517)$ \\
\hline $16(23)$ & $500(461)$ & $153(214)$ & $12(34)$ & $33(48)$ & 22 & 25563 (37669) \\
\hline $17(24)$ & 1395 (2113) & $320(689)$ & $66(88)$ & $2880(3180)$ & 42 & 13468 (11302) \\
\hline $18(20)$ & $1410(1246)$ & $29(65)$ & $46(78)$ & $195(308)$ & 25 & $43020(43515)$ \\
\hline
\end{tabular}

\section{PCA case scores}

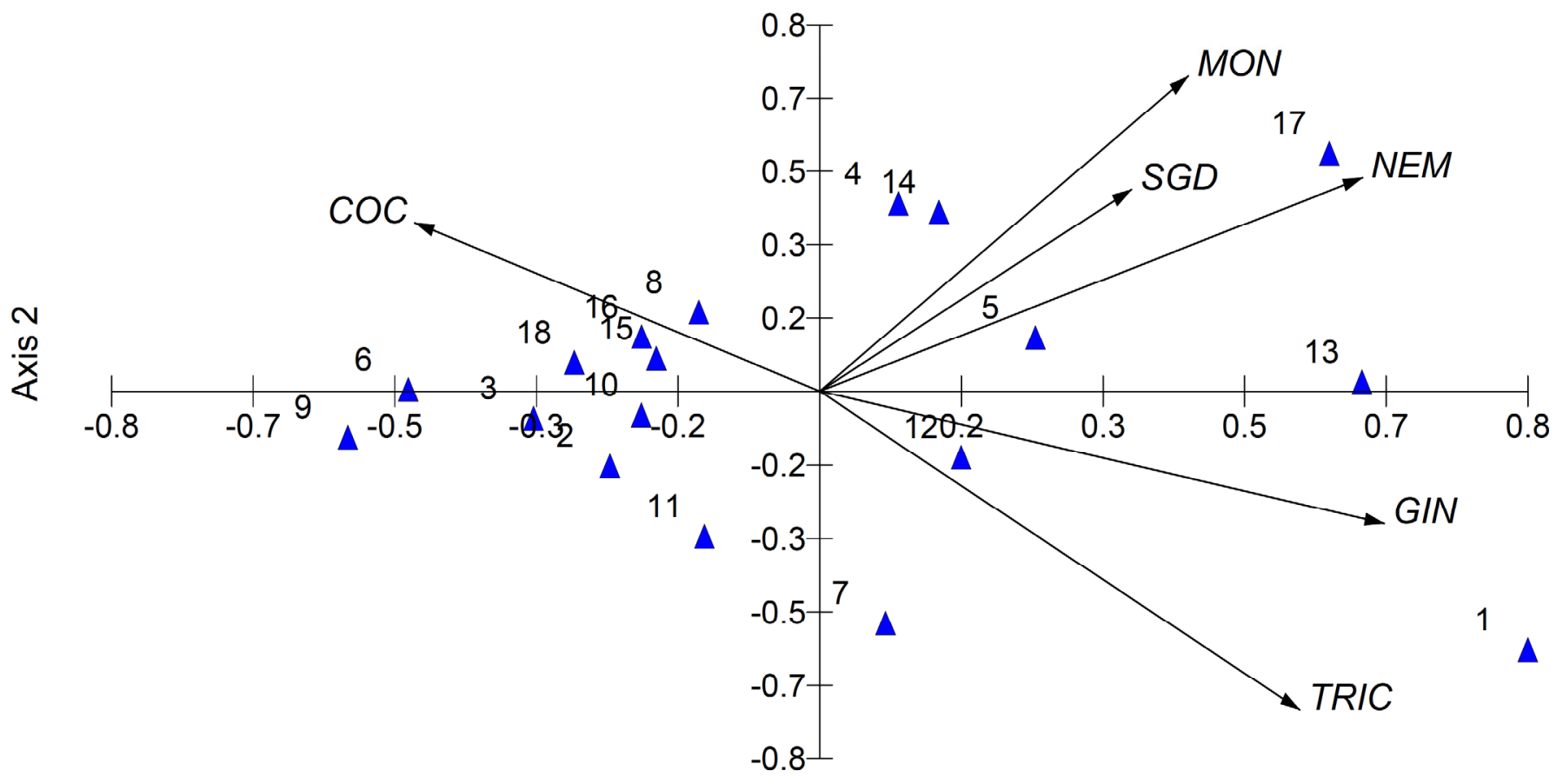

Axis 1

Fig. (1). Description of parasitism and similarity between farms (numbers): Euclidean biplot based on principal component analysis. 
Table 2. Comparative Parasite EPG/OPG and FAMACHA ${ }^{\odot}$ in the Three Categories of Lamb Condition as Judged by the Farmers' Eye Score

\begin{tabular}{|c|c|c|c|c|c|c|c|}
\hline Farmer Eye Score (No. of Lambs) & GIN & NEM & TRIC & SGD & MON & COCc $^{\text {FAMACHA }}$ \\
\hline \hline Good (76) & 937 & 106 & 40 & 356 & 22 & 26027 & 2,8 \\
\hline Average (108) & 1064 & 163 & 69 & 439 & 30 & 17695 & 2,3 \\
\hline Poor (163) & 1205 & 90 & 78 & 395 & 28 & 14796 & 2,1 \\
\hline Statistical significance & $\mathrm{p}=0.89$ & $\mathrm{p}=0.07$ & $\mathrm{p}=0.01$ & $\mathrm{p}=0.56$ & $\mathrm{p}=0.01$ & $\mathrm{p}=0.48$ & $\mathrm{p}=0.00$ \\
\hline
\end{tabular}

Table 3. Farmers' Eye Score in Relation to Gastrointestinal (GIN), Nematodirus (NEM) and Strongyloides (SGD) Egg Per Gramme of Faeces (EPG) and Farms (Nominal Regression of Farmers' Eye Score with GIN, NEM, SGD, Farm)

\begin{tabular}{|c|c|c|c|c|}
\hline GIN EPG & Number of Farmers' Eye Score & Significance of Model Fit & Cox and Snell R $^{\mathbf{2}}$ & Significant Factors $^{\text {NEM; Farm }}$ \\
\hline \hline$>200$ & 269 & 0.006 & 0.25 & NEM, Farm \\
\hline$>500$ & 152 & 0.080 & 0.26 & NEM, Farm \\
\hline$>1000$ & 99 & 0.005 & 0.45 & NEM, SGD, Farm \\
\hline$>1500$ & 78 & 0.009 & 0.55 & \\
\hline
\end{tabular}

in areas dominated with Haemonchus infections [4, 12] but is not as efficient in other places [13]. Although Haemonchus; were present on the farms included in the present study, it was at a relatively low level (10-15\% of the worms) [2]. This perhaps explains the low efficacy of FAMACHA ${ }^{\odot}$ method in our study.

How the farmers' score was obtained was not investigated in this study. It is likely a large amount of information is taken into consideration by the farmer [14], consciously or sub-consciously, making it difficult to either quantify or qualify the factors which form the basis for decisions for each individual farmer. Most organic farmers are willing to find their own solutions for managing flock health, parasitic infections included [6], and they do not easily accept and use pathophysiological indicators [15, 17]. One solution was to let them propose their own solutions, what we called the farmers'eye score. As this was not found to be strongly related to gastrointestinal parasitic infection (except for Strongyloides, Moniezia, Trichuris and possibly Nematodirus, depending on analyses) it suggests that some progress could be made by incorporating pathophysiological indicators in the lamb category rated as poor [16]. When the farm was included as a factor in nominal regressions (Table 3) only Nematodirus was constantly related to farmers'eye score. It means that the farmers'eye score is probably related to gastrointestinal infection and particularly Nematodirus but also depends on the variability of evaluation among farmers.; harmonisation of scores is necessary. The poor category represented nearly $50 \%$ of the flock and it probably overestimates the proportion of lambs needing treatment. This proportion should not exceed 20 to $30 \%$ in TST, as it is repeated monthly [3]. Farmers need to improve and harmonise their ability to detect lambs in need of treatment if the farmers' eye score is to be used effectively in future.

\section{ACKNOWLEDGEMENTS}

We are grateful to all the organic farmers that participated in this survey. The « Laboratoire départemental d'analyses et de recherche, Limoges » did all the faecal helminth eggs and oocysts counts. The construction of the methodology for detecting the animals in need of anthelmintic treatments and based on farmer decision and knowledge is a part of the ongoing French ANR programme DynRurABio on organic farming.

\section{REFERENCES}

[1] Benoit M, Laignel G. Constraints under organic farming on French sheep meat productions: a legal and economic point of view with an emphasis on farming systems and veterinary aspects. Vet Res 2002; 33: 613-24.

[2] Cabaret J, Bouilhol M, Mage C. Managing helminths of ruminants in organic farming. Vet Res 2002; 33: 625-40.

[3] Cabaret, J. Pro and cons of targeted selective treatment against digestive-tract strongyles of ruminants. Parasite 2008; 15: 506-9.

[4] Van Wyk J, Bath G. 2002. The Famacha ${ }^{\circ}$ system for managing haemonchosis in sheep and goats by clinically identifying individual animals for treatment. Vet Res 33: 509-29.

[5] Cabaret J, Benoit M, Laignel G, et al. Current management of farms and internal parasites by conventional and organic meat sheep French farmers and acceptance of targeted selective treatments. Vet Parasitol 2009; 164: 21-9.

[6] Nicourt C, Cabaret J. Création de normes, innovation sanitaire et éthique des éleveurs ovin bio. p85-98. In: Le travail en agriculture : son organisation et ses valeurs face à l'innovation. Eds P. Béguin, B. Dedieu, E. Sabourin. 2011, Lharmattan, Paris p. 301.

[7] Cabaret J, Benoit M, Laignel G, et al. Health advisors in organic meet sheep farms: the role of the veterinarians. The Open Vet Sci J 2011 ; in press

[8] Cabaret J, Mage C, Bouilhol M. Helminth intensity and diversity in organic meat sheep farms in centre of France. Vet Res 2002; 33: 625-40.

[9] MAAF. Manual of Veterinary Parasitological Laboratory tecohniques.1986. HMSO $160 \mathrm{p}$.

[10] SPSS statistical package. User's Manual. Version 11.5

[11] Multivariate statistical package (MVSP). Users' Manual. Version 3.1. 137 pp. Kovach Computing services, Pentraeth 2001.

[12] Kaplan RM, Burke JM, Terrill TH, et al. Validation of the FAMACHA eye color chart for detecting clinical anemia on sheep and goat farms in the southern United States. Vet Parasitol 2004; 12: $105-20$.

[13] Koopmann R, Holst C, Epe C. Experiences with the FAMACHAEye-Colour-Chart for identifying sheep and goats for targeted anthelmintic treatment. Berl und Münch Tierärzt Wschrift 2006; 119: 436-42. 
[14] Salmona M. Les paysans français. Le travail, les métiers, la transmission des savoirs. Paris: L'Harmattan 1994; p. 371.

[15] Van Wyk A, Hoste H, Kaplan RM, et al. Targeted selective treatment for worm management-How do we sell rational programs to farmers? Vet Parasitol 2006; 139: 336-46.
[16] Ouzir M, Berrag B, Benjouad A, et al. Use of pathophysiological indicators for decision of anthelmintic treatment of ewes against gastro-intestinal nematodes in Morocco. Vet Parasitol 2011; 180, 372-77.

[17] Russel A. Body condition scoring of sheep. In Practice 1984; 6: 91-3.

(C) Bouilhol et al.; Licensee Bentham Open.

This is an open access article licensed under the terms of the Creative Commons Attribution Non-Commercial License (http://creativecommons.org/licenses/by-nc/3.0/) which permits unrestricted, non-commercial use, distribution and reproduction in any medium, provided the work is properly cited. 